\title{
A ATUALIDADE DA FILOSOFIA POLÍTICA: A TENSÃO ENTRE DIREITO E SOCIEDADE EM HEGEL E LUHMANN
}

\author{
Danilo Vaz-Curado R. M. Costa \\ PPGFIL -UFRGS/FG
}

\begin{abstract}
Our objective is na critical aproach with Hegel and Luhman as alternatives to compreend the tension between Society na State, on modern times. Especificaly, our essay will evaluate the potencial product of Hegelian and Luhmaniana comprehension over law and society, and how the interactive ways of this models of conceptual construction of sociability, are comprehended as theorical marks. Assuming that Hegel understands society and law as an holisitic system of self-diferentiation and self-reflexion, and Luhman's overview of law and society operates on a self-refering mark. The final objective is to present a critical judgement of this contributions and their relevant aspects over the debate about tension in the relation between Socienty and law.
\end{abstract}

Keywords: contemporary, philosophy of law, society, law.

Resumo: Objetivamos aproximar criticamente Luhmann e Hegel como alternativas de compreensão da tensão entre Sociedade e Estado na contemporaneidade. Especificamente nosso trabalho avaliará o potencial produtivo da compreensão Hegeliana e Luhmanniana de direito e sociedade e, como os modos interacionais entre estes modelos de tradução conceitual da construção da sociabilidade são compreendidos nos seus respectivos marcos teóricos. Partiremos do pressuposto de que Hegel compreende sociedade e direito enquanto sistema holístico de autodiferenciação e autoreflexão e que em Luhmann, sua compreensão de direito e sociedade se opera num marco compreensivo autoreferente. Espera-se ao final apresentar juízo crítico destas contribuições e seus aspectos relevantes ao debate acerca da tensão entre sociedade e direito.

Palavras-chave: contemporaneidade, filosofia do direito, sociedade, direito. 


\section{Introdução}

O presente trabalho objetiva demonstrar como a filosofia política possui atualidade e potencial de diagnose acerca do real, podendo estabelecer as condições de reconhecimento das estruturas institucionais, orientando a ação de seus constituintes. Tal desiderato se buscará demonstrar mediante a aproximação conflitiva ou agônica de 2 clássicos pensadores - Hegel e Luhmann, ou melhor, pensadores limites. Hegel considerado por muitos o expoente do idealismo alemão, filósofo da totalidade e da revolução francesa e Luhmann o cientista social da teoria dos sistemas e das teorias comunicacionais; o primeiro - Hegel - combatido ferozmente por Schelling, o segundo - Luhmann - vítima da inquisição harbemasiana acerca de um suposto conservadorismo de sua teoria dos sistemas.

Para aproximar criticamente Luhmann e Hegel e a partir deste encontro demonstrar a atualidade da filosofia poítica, precisaríamos de um metron, tal denominador comum em nosso texto será a compreensão da tensão presente entre o Direito [Recht] e a Sociedade [Gesellschaft] na contemporaneidade desde as contribuições hegelianas e luhmannianas. $\mathrm{O}$ fio condutor desta aproximação é a compreensão hegeliana do 'espírito objetivo' [objektive Geist], através do qual, (i) a realidade social e as suas normas não são redutíveis às ações, intenções ou interesses dos seus agentes e (ii) leis e normas não se constituem enquanto meras convenções, porém determinidades da razão.

Neste contexto o espírito objetivo nos permite o necessário ponto de encontro entre Hegel com Luhmann e sua teoria sistêmica. Mais especificamente, nosso trabalho avaliará o potencial produtivo da compreensão Hegeliana e Luhmanniana de direito e sociedade e, como os modos interacionais entre estes modelos de tradução conceitual da construção da sociabilidade pela ótica da filosofia política são compreendidos nos seus respectivos marcos teóricos, de modo a que, os pressupostos e o desenvolvimento dos modelos - de Hegel e de Luhmann - se iluminem reciprocamente e nos permitam compreender as razões do permanente embate entre o Direito e a Sociedade, para destas inquirições e das conclusões daí advindas demonstrar a potencialidade da filosofia política na contemporaneidade.

Partiremos do pressuposto de que Hegel compreende o Direito, no marco do seu conceito de Espírito Objetivo, enquanto sistema holístico de 
autodiferenciação e autoreflexão a partir da atividade do conceito de açãorecíproca [Wechselwirkung], entre interações individuais versus processos sociais e instituições estatais, para assim, apontarmos o papel fundamental de autocompreensão dos conceitos de Direito e Sociedade em Hegel e sua tensão constitutiva oriunda de sua teleologia imanente.

Em Luhmann partiremos do pressuposto de que sua compreensão do Direito e da Sociedade se opera num marco de compreensão autoreferente, de modo que pautaremos nossa análise compreensivo-delimitatória dos conceitos de Direito e Sociedade em Luhmann, desde o papel da Reflexão e seu desdobramento em referência a $S i$ [Selbstbeziehung] e referência ao outro [Fremdbeziehung] e assim, demarcaremos o conceito Luhmanniano de Sociedade, processo evolutivo de comunicação, face ao seu conceito de Direito, elemento por excelência redutor da contingência social e as tensões operadas e oriundas de uma proposta sistêmica não-teleológica.

Postos estes dois modelos filosófico-político de compreensão da realidade e suas premissas delimitatório-explicativa, buscaremos uma resposta as relações oriundas do enlace entre Direito e Sociedade como modus ponens de atualidade do discurso da filosofia política.

Espera-se ao final podermos apresentar um juízo crítico sobre estas contribuições, apresentando seus aspectos relevantes ao intenso debate acerca da tensão presente na relação entre sociedade e direito.

\section{Modelos sistemáticos de compreensão do real: Hegel e Luhmann}

A aproximação de dois autores com o objetivo de análise de sua obra sobre um tema comum, sempre corre o risco da apreensão unilateral da obra de um, ou, de ambos os autores estudados; risco maior corre-se quando os autores em comento se propõem a uma atitude autocompreensiva e sistemática do real.

Sabendo do presente risco, ousamos afirmar sem dúvida que tal dificuldade - a compreensão sistemática - ao contrario, é na verdade uma forte fonte de condições de possibilidades, e neste primeiro momento objetivamos exatamente traçar as condições gerais desta aproximação, segundo diretrizes formais, as quais tornarão, esperamos, factível o nosso propósito.

Hegel e Luhmann são autores que propõem uma compreensão filosófica do fenômeno jurídico-político, entendido o jurídico como não 
redutível à norma, a qual em termos gerais se expressa mediante a tensão entre a Sociedade e o Estado, no seio de sua compreensão sistemática do real. Poderíamos afirmar que em síntese, o Direito [Recht] nos dois autores expressa o próprio processo de autoreflexão a si do Social mediante complexos fenômenos individuais e coletivos, e a Sociedade [Gesellschaft] é a unidade institucional que no meio de processos agonísticos estabelece - por autoconstituição - núcleos de sociabilização coerentes, cogentes e direcionados a sua unidade, pela via do sistema jurídico - O Direito [Recht].

Deste modo, o Direito e a Sociedade expressam momentos de realização, ou esferas, onde mediantes instâncias próprias e autodelimitadas as relações são instituídas e se concretizam, estabelecendo reciprocamente as condições de sua efetividade e os processos de sua degradação. A sociedade é a ação [Handlung] mediante o qual o Direito se institui, o Direito é a atividade [Tatigkeit] na qual o social adquire centralidade e referência a Si. O atuar [Tun] unitário destas instâncias expressa a tensão entre a abertura do social e a completude do Direito, demonstrando-se o sistema numa paradigmática estrutura sistemática, ao mesmo tempo, aberta e fechada.

Porém, antes da própria problematização e posterior aproximação entre Hegel e Luhmann, segundo os pressupostos que traçamos, fica a pergunta sobre o que é um sistema? Em traços largos diríamos que - o sistema - é um modo de compreensão da realidade que se constitui na história da filosofia desde a compreensão platônica das idéias exposta em seu diálogo Fédon e que paradoxalmente parecia haver sido extinta com o idealismo hegeliano.

Contudo, tal assertiva supra, peca pela exterioridade e de modo a complementar a compreensão do que desejamos expressar ao afirmarmos 'sistema', arremataríamos que o sistema é um modelo de compreensão da realidade mediante a autodiferenciação de seus elementos os quais determinados pelo todo, reciprocamente o determinam de modo a que neste processo de autorecursividade, das partes e do todo, constitua-se a Totalidade sistemática como uma identidade autoreflexiva.

Deste modo o sistema constitui-se como uma unidade na qual seus elementos se relacionam em processos de determinação por diferenciação a si, autônomos, e que os mesmos realizam-no num processo de particularização do universal; todavia, tal processo de identidade apenas possui efetividade porque suportado pela unidade do todo. O sistema no processo de diferenciação a si de seus elementos constituintes se designa como fechado. 
Contudo, há uma segunda ordem de atividades no seio de uma compreensão sistemática que se constitui pela autoatividade [Selbstätigkeit] do sistema a si, a qual, promove não a relação das partes em seu processo de afirmação negativa, mas que constitui a totalidade, enquanto unidade pela própria relação do sistema enquanto uno subsistente a si face as suas determinidades autônomasou seja, o momento aberto do sistema.

Dentro deste dúplice processo; (i) relação das partes em sua dinâmica de constituição da identidade sob o pano de fundo da totalidade sistemática e (ii) a relação da totalidade do sistema face as suas determinidades constituintes, desenvolve-se o elemento vivo no qual se estrutura, em nosso estudo a tensão entre o Direito e a Sociedade. Neste movimento reflexivo constitui-se reciprocamente o todo e as partes, de modo que, institui-se uma recursividade por duplicidade; coexistindo os momentos aberto e fechado do sistema numa totalidade autônoma e ao mesmo tempo dependente de Si. No sistema tal como propomos dependência e autonomia se autocondicionam.

Dentro de qualquer concepção sistemática o grande nó górdio é a relação do todo com as partes, destas entre si e do todo consigo mesmo [enquanto unidade idêntica na diferenciação de Si], ou, nos limites do nosso propósito, da relação entre Direito e Sociedade.

Segundo nossa leitura é a própria tensão entre o fato e a norma, para utilizar uma linguagem sociológica, ou segundo o nosso marco, entre Direito e Direito, que estabelecem as condições da recursividade do todo social.

O Problema da auto-atividade [Selbstätigkeit] no seio de uma compreensão sistemática não deve sob hipótese alguma descurar da unidade que deve subsistir, como condição sine qua de sua própria autorelação [Selbsvehältnis], mas tal estruturação da atividade sistemática não pode também pré-determinar a própria ação dos sub-sistemas, de modo que

Uma tal unidade deve ser pensada processualmente, e as relações dos elementos entre si devem referir-se a uma autoreferencialidade, a fim de que os elementos não obtenham primazia diante da unidade. Esta relação não deve ser pensada nem de modo causal nem teleologicamente. Ao contrário, o processo estabelece a unidade (NEUSER, 1994, p. 63).

Feitos tais prolegômenos necessários a delimitação do embate entre os conceitos e os problemas a serem desenvolvidos, nos lançamos agora ao 
nosso propósito de aproximação e ao mesmo tempo demarcação das propostas e respostas à tensão entre Direito e Sociedade em Hegel e Luhmann. Advertimos que toda nossa posterior análise tem por pressuposto este compreensão de realidade sistemática descrita.

\subsection{Hegel: o Espírito Objetivo e a tensão entre Sociedade e Direito.}

É lugar comum a afirmação de que Hegel é um filósofo sistemático e que a compreensão de seu intento exige uma pequena e prévia compreensão do estatuto de sistema para Ele. Nos propomos com o risco que tal empreitada oferece, a expor uma breve consideração sobre sistema em Hegel, para em seguida delimitar em que consiste o 'Espírito Objetivo' e apresentar a tensão existente entre Sociedade e Direito em Hegel como elemento atual de sua filosofia política.

Hegel apresenta sua compreensão sistemática do real numa obra intitulada Enciclopédia das Ciências Filosóficas, a qual possuiu 3 edições em vida, respectivamente em 1817, 1827 e $1830^{1}$, onde ele desenvolve seus sistema e o relacionar-se interno do sistema consigo mesmo. Tal autoorganização do sistema hegeliano opera-se em seu estágio mais alto sob a expressão do Espírito [Geist], o qual desenvolve-se sob três sub-sistemas interdependentes: Lógica, Filosofia da Natureza e Filosofia do Espírito. A lógica expõe a auto-exposição do Espírito no âmbito do puro pensar, a Natureza é extrusão [Entäusserung] do Lógico no extremamente outro de simesmo, na alteridade irreconciliável da natureza, e a reconciliação do Lógico com o Natural é o reino do Espírito, o qual seguindo o intuito e o programa da filosofia hegeliana, se autodetermina [Selbstbestimmtheit] em outros três momentos: Espírito subjetivo, objetivo e absoluto.

Deste modo o sistema de Hegel possui 3 formas da existência: lógica, natureza e Espírito, ao mesmo tempo em que se conhece por outros três modos; Espírito subjetivo, Objetivo e Absoluto, os quais promovem no seu tríplice movimento uma verdadeira suprassunção [Aufhebung] de todos os momentos anteriores.

\footnotetext{
1 Para uma compreensão atual do estado da arte sobre a relação entre método e sistema em Hegel, Cf. Ernst-Otto Onnasch, System und Methode in der Hegels Philosophie, pp 79-90, in Logik, Mathematik und Natur im objektiven Idealismus: Festschrift für Dieter Wandschneider, Verlag Königshausen \& Neumann $\mathrm{GmbH}$, Wurzburg, 2004.
} 
O Espírito enquanto modo de autoconhecer [Selbsterkennen]do sistema é o resultado necessariamente livre da Lógica e da Natureza. De modo que se na lógica, estamos no puro pensar em seu processo de autodeterminação necessária e, na natureza o lógico se exterioriza, sendo a natureza o outro de si mesmo em sua exterioridade; a própria natureza é a preparação e a dedução do lógico na sua extrusão [Entäusserung] no mundo exterior, a qual se efetiva com e no Espírito.

Desta forma, o primeiro momento do Espírito é ser a verdade da natureza, Espírito Subjetivo, ou, o social visto sob a constituição do indivíduo; o seu segundo momento é a suprassunção do Espírito como verdade da natureza, onde a natureza aparece [Erschneinnung] como a verdade do Espírito e o indivíduo que neste estágio se visualiza a partir das interações que lhe são constituintes no Social. Agora a natureza não é mais compreendida em sua forma imediata, mas sim a natureza entendida como mediação a Si ou cultura [Bildung], objetividade do relacionar-se livre da liberdade em instituições, ou em linguagem hegeliana: Espírito Objetivo ${ }^{2}$, ou seja; Família, Sociedade Civil [Bügerlichgesellschaft] e Estado [Staat]. ${ }^{3}$

Ao adentrar na Filosofia do Espírito as autodeterminações [Selbstbestimmtheit] do Espírito são suprassumidas [Aufhebung] num contínuo processo que conduz do Espírito ao próprio Espírito. Nosso intento situa-se exatamente no Espírito Objetivo, segunda forma do autoconhecer do Espírito, momento de mediação da subjetividade livre face a totalidade reflexiva a si das instituições, para assim, bem no centro do sistema hegeliano - sua filosofia política - buscar mapear sua tradução conceitual da realidade e como desta conceitualização emerge a contradição e a tensão das esferas da Sociedade e do Direito.

Em Hegel a Sociedade ou a sociedade civil burguesa, numa tradução literal do vocábulo, se constitui por dois princípios: (i) a atividade do indivíduo como fim em si mesmo, sendo sua autonomia a condição de sua realização nas diversas esferas de sua atuação, $v \cdot g$ o trabalho, as corporações, o estado etc., e (ii)a universalidade abstrata oriunda deste aspecto autocentrado da subjetividade.

\footnotetext{
2 Para uma compreensão atual da tensão entre Sociedade e Direito em Hegel tendo como marco epistemológico o Espírito Objetivo, é assaz importante a leitura do livro do Prof. Kervégan, L'effectif et le rationnel - Hegel et l'esprit objectif. Paris: Vrin, 2008.

${ }^{3}$ Não se deve confundir em Hegel, Staat tal como hoje designamos o Estado, com Stand.
} 
A sociedade promove a realização e constituição da consciência e do querer individual, espaço prioritário para as ações e interesses conscientes dos atores sociais, ao mesmo tempo em que, promove o início do sentimento de pertença à comunidade[ [Gemeinde $]^{4}$.

O trabalho, a satisfação e o querer individual se exercitam por excelência nos jogos e modos interacionais próprios da sociedade. Contudo a realização destas condições individuais de realização do sujeito que é fim em si mesmo esbarra em outras intenções e mecanismos de satisfação, ocasionando a estruturação de uma sociabilidade fragilizada, imposta por um modo de reconhecimento [Anerkennung] assimétrico, ao qual a própria estrutura social é incapaz de equalizar.

Este postulado da desigualdade inicial cumulado com a busca igualitária, ou melhor, homóloga de realização de si exige mecanismos de mediação que se façam capazes de equalizar o exercício deste $\mathrm{Si}$ das subjetividades que interagem nos contextos sociais, e este mecanismo é a elevação [Erhebung] da satisfação individual ao estágio não do querer subjetivo, mas de uma ordem racional que preservando a vontade privada, reflita sobre os postulados que a orientam e se exercite como o querer racional da comunidade.

A sociedade orienta-se pelo exercício satisfativo das necessidades e não pela finalidade que se objetiva no exercício desta vontade, e é esta contradição que aproxima a sociedade de uma desordem generalizada ${ }^{5}$, onde a vontade se choca com outra vontade e nesta generalização dos conflitos e das pretensões resultantes do exercício das vontades singulares, o todo social pode perecer.

A sociedade estrutura-se como a realização do querer em coisas exteriores [coisas] e determinações da vontade [valores], neste momento ocorre a passagem no social do querer à ação, ou seja, no atuar da vontade sua liberdade consiste em se dar suas determinações; seu querer transformar-

\footnotetext{
${ }^{4}$ Não se deve confundir em Hegel, (I) comunidade [Gemeinde], condição na qual a subjetividade pode se realizar como objetividade, ou a elevação [Erhebung] da particularidade à universalidade concreta com a (ii) sociedade [Gesellschaft] momento da afirmação da individualidade e de sua dispersão, onde 0 indivíduo enquanto sujeito encontra-se submetido aos princípios da eficácia e da eficiência, oriundo do mundo do trabalho, onde a a atividade da individualidade, mesmo que interacional, sempre é uma universalidade abstrata.

${ }^{5}$ L. Siep, in Die Aktualität der praktischen Philosophie Hegels.p 192, afirma que Hegel em sua concepção da Sociedade como sistema das necessidades [,System der Berdufnissen"] e sua valoração do mundo do trabalho [Arbeitswelt] antecipou as condições de visualização da tendência à globalização e das crises econômicas.
} 
se em propósito e intenção. Ocorre que o querer enquanto momento interno da vontade que se realiza em coisas exteriores, e o propósito e a intenção enquanto vontade exteriorizada que se realiza interiorizando-se a si mesma, momento da Sociedade Civil, ainda são como que acidentes [pessoas] que se realizam na substância [estado], incapazes de compreenderem-se.

Assim fecha-se o mecanismo da Sociedade, enquanto relacionar-se de indivíduos uns com os outros à modalidade da universalidade formal de pessoas autônomas, ou em termos hegeliano, a sociedade é o estado exterior.

Nesta insuficiência do social de ser vontade livre que atua segundo fins autodeterminados, as subjetividades instituem no ocaso [Zufall] de seu atuar na sociedade mecanismos que transcendem a mera reflexão sobre si individual, ou seja, institui-se uma consciência moral coletiva ou uma comunidade de valores. Essa passagem do individual-social ao socialmediatizado, corresponde em nosso texto ao transitar [Übergehen] da Sociedade ao Direito. E é neste passagem que transitamos de uma mera filosofia axiológica ao uma verdadeira filosofia política, pois ao valores emergem ao estágio de reflexão global sobre si, ou seja, os valores se refletem não mais individualmente mas socialmente, passa-se da moralidade à eticidade.

Hegel compreende o Direito num sentido similar ao Estado, contudo, não ao estado enquanto aparato de normas, aparelho burocrático ou mecanismo de coerção e administração do social. Pois sendo o Estado para Hegel tudo isto, transcende este conceito pragmático-utilitarista, numa concepção lógico-metafísica. Para Hegel, o Estado é a unidade entre a vontade singular e a vontade substancial ${ }^{6}$ desenvolvido numa unidade orgânica que se refere a si mesmo [à sociedade] e às outras unidades [outros países ou estados], onde a vontade singular se identifica com a vontade substancial por ser a vontade o racional em si [individual-social] para si [social-mediatizado], ou, a subjetividade que age por que sabe as razões de seu agir.

No $§ 539$ da sua Enciclopédia das Ciências Filosóficas afirma Hegel que

${ }^{6}$ Ou seja; a unidade entre a vontade do indivíduo e do Estado enquanto aparelho burocrático, coercitivo, fiscalizatório, legisferante etc. 
O Estado como espírito vivo, absolutamente só é como um todo organizado, distinto em atividades particulares, que procedem do conceito único (embora não sabido como conceito) da vontade racional, produzem continuamente esse todo como o seu resultado (Hegel, Enz III § 539).

Desta feita, o Direito em Hegel é este conceito amplo de estado que coordena as diversas esferas da sociabilidade segundo normas estruturadas nestes diversos subsistemas do espírito [Geist], v.g o amor na família, o querer livre na sociedade, a vontade mediatizada no estado; acrescido da atividade da ação recíproca de integração do social no estado e vice-versa, mediante o reconhecimento implícito e explícito às normas por seus destinatários e constituintes.

Os atuais exegetas hegelianos afirmam que na tensão existente entre Sociedade e Direito em Hegel, o projeto hegeliano falhou exatamente porque descurou da

[...] diferença irreconciliável de princípios antagônicos próprios ao social - enquanto constituído pelo indivíduo que é fim em si mesmo - e ao político - momento de reconciliação mediada do subjetivo face ao objetivo. A Sociedade civil e suas aporias constitutivas, [...] põem as condições de efetivação do Político, sendo reciprocamente a causa da vitalidade e das falhas do social na medida em que afirma e põe as contradições do agir moderno como a reposição da universalidade presente nas instituições objetivas a partir dos déficits da particularidade presentes na sociedade civil burguesa, aos moldes de uma Eticidade perdida em seus extremos (Costa, 2009, p.278)

Contudo parece-nos que é mais acertado afirmar que Direito em Hegel expressa um modo de ordenamento do social concebido teleologicamente e ao mesmo tempo normativo, onde os estratos da liberdade (civil e política) se relacionam e se realizam em atividade recíproca na história.

Neste contexto, parece-nos que Hegel promove a diagnose da moderna tensão entre a sociedade e o Direito, concernente ao emergir da subjetividade e de seu processo de autocertificação racional do mundo da vida, a qual ao 
estabelecer o social; as práticas de sociabilidade são subsumidas pelo direito numa espécie de legalidade do social, reduzindo a esfera do social aos códigos e ritos determinados na esfera do Direito. Neste acoplamento por submissão da Sociedade pelo Direito reside a constatação de diagnose da Filosofia Política hegeliana e ao mesmo tempo sua falha, pois para Hegel a tarefa da filosofia sendo apenas a tradução do tempo em conceitos, não deve a filosofia política apontar alternativas a este fenômeno.

\section{2 - Luhmann: autopoiese e a tensão entre sociedade e direito.}

Niklas Luhmann é seguramente um dos maiores pensadores da contemporaneidade, possuindo uma obra que abarca análises desde a recepção dos conceitos iluministas nas ciências do espírito [Geistswissenschaft] até as relações sistemáticas de compreensão da realidade social e política.

Nosso intento objetiva demonstrar como Luhmann apresenta sua resposta para a relação belicosa ou agonística vivida entre o Direito e a Sociedade; desta forma temos como momento prévio de analise a demarcação, ao menos, do conceito de autopoiesis e de sistema para o autor.

Autopoiesis é uma palavra grega composta de dois termos que em síntese significam a criação por si, ou, a produção autônoma. Segundo Luhmann a autopoiese se realiza todas as vezes em que é possível individualizar um processo interno, ao mesmo tempo que, mediante tais processos um organismo ou sistema se torne capaz de manutenção e reprodução por si.

A autopoiese enquanto atividade de autodeterminação e reprodução de um sistema condiciona-o aos limites do entorno e da compatibilidade que se realiza mediante trocas entre os subsistemas que o compõe, em nosso caso buscaremos demonstrar como 2 subsistemas - Direito e Sociedade - se comunicam e se tencionam reciprocamente.

Para Luhmann a Sociedade [Gesellschaft] é um processo evolutivo dos modos de realização comunicativa mediante o qual se altera a linguagem mesma e os modos de descrição lingüísticas do seu entorno, Segundo Trindade a "[...]sociedade é um sistema social que possui o mais elevado grau de auto-suficiência em relação ao meio ambiente” $(2008,32)$.

Deste modo Luhmann compreende a sociedade como uma rede onde diversos códigos lingüísticos se interpenetram de forma que o sujeito é uma 
espécie de conceito funcional dotado de um componente extremamente ideológico. ${ }^{7} \mathrm{Na}$ teoria Luhmanniana a sociedade moderna estrutura-se sob a forma de um sistema autoreferente que diferencia-se funcionalmente face a si e a seu entorno mediante estruturas lingüísticas.

Assevera Luhmann que "[...] o sistema social, enquanto sistema estruturado de ações relacionadas entre si através de sentidos, não inclui, mas exclui o homem concreto."(1983 I, p.169)

Observa-se, portanto que para Luhmann a sociedade resultante do estado de direito é realizável apenas em parte, pois acopla em si estruturas pré-modernas com a tarefa de atingir resultados contemporâneos, de modo que sua base estrutural está diametralmente oposta aos anseios de seus componentes finais.

Deste modo a teoria dos sistemas luhmanniana desintegra a sociedade em diversos subsistemas que se coordenam reciprocamente mediante trocas simbólicas e funcionais em razão de que a atividade e a interação se coordene inter partes aos subsistemas e se subordine face a totalidade sistemática. $\mathrm{O}$ Direito segundo Luhmann é um subsistema funcional que objetiva conter a desregulação a que está submetida a sociedade reduzindo os conflitos e assegurando a sociabilidade mediante a contingência.

O Direito para Luhmann é um momento funcional sistemático ou subsistemático da Sociedade que objetiva manter estáveis as expectativas dos atores sociais em contextos instáveis determinados. O Direito possui a função de diluir ou esvaziar o conflito ao mesmo tempo em que paradoxalmente contribui para a sua perpetuação, pois toda a estabilização do conflito, no âmbito do direito, se opera segundo códigos comunicativos da linguagem binária submetidos no máximo a apenas 2 valores de verdade [verdadeirofalso] com a preservação da estrutural conflitual, mediante a imposição de um comando face a submissão do outro.

Este papel redutor da complexidade e da contingência, mediante o direito, próprias das sociedades contemporâneas se realiza enquanto instância temporal de garantia e asseguramento das expectativas sociais mediante imputações objetivas procedimentais que discriminam condutas e tornam realizáveis projeções interacionais, mesmo em contexto de dúplice

${ }^{7}$ Cf N. Luhmann, Die Gesellschaft der Gesellschaft, II, p.1025. 
contingência - psíquica e social - estabilizando relações e operacionalizando comportamentos.

Assim, se estivermos correto, do entrelaçamento ou acoplamento entre a Sociedade e o Direito e deste relacionar intrinsecamente recíproco, o sistema possui autoreferência [Selbstbeziehung], consistente na compreensão reflexiva a $\mathrm{Si}$ do sistema face a seu entorno, e/ou do sistema face a seus componentes estruturadores.

Da autoreferência [Selbstbeziehung] resultante da tensão entre Sociedade e Estado perpassados pelo Direito, Luhmann designa como o sistema estabelece duas estratégias de redução da complexidade, uma de ordem cognitiva e outra de via normativa. Assim Luhmann estrutura como atividade da sociedade um dúplice processo, pois no ato em que a Sociedade se autoreconhece, ao mesmo tempo Ela também se autolimita.

Contudo ao compreender o Direito como um subsistema relacionante e relacionado a outros subsistemas funcionais, como v.g. a Economia, a Religião etc., que como Ele - o Direito - também são autoreferenciais, surge a dificuldade do modelo Luhmanniano e que se põe como nosso problema: como pode o direito se coordenar de modo a alcançar sua efetividade e legitimidade se seu telos é o esvaziamento do conflito, mas sua legitimação não pode se realizar senão com fulcro apenas em si mesmo [an sich selbst]?

O Direito enquanto subsistema coordenado a conduzir a Sociedade mediante a redução de sua contingência e da indeterminação dos processos sociais o faz mediante a instauração de uma outra tensão constitutiva, aquela que se instaura pela formalização do mundo da vida e da radicalização dos processos sociais face a uma extrema racionalização deste mesmo processos. As contingências totivalentes se reduzem a estruturas contingenciais binárias.

Parece-nos que no modelo de Luhmann o Direito reconhece o aspecto agonístico, mas o subjuga, modalizando o mundo da vida segundo prescrições comportamentais sobre o justo e o injusto [recht und unrecht], formalizando-o. Segundo Höffe (2007,37), Luhmann incorre em sua delimitação do Direito em uma tríplice ilusão de perspectiva [eine dreifache perspecktivische Täuschung], por ignorar alguns aspectos históricos em sua reconstrução lógico-sistemático e categorial de seus elementos formativos, entre os quais; a democracia ateniense, a justiça como aspecto definidor do direito e por compreender o direito como uma estrutura pré-moderna, vindo Luhmann segundo Höffe $(2007,38)$, apenas em sua obra de maturidade Ausdifferenzierung des Rechts a assumir um conceito de Direito capaz de 
por sua diferenciação interna resultante da complexificação sistêmica atingir um padrão de complexidade adequada. ${ }^{8}$

Neste sentido a Sociedade se diferencia internamente pelo Direito, num claro processo autopoiético entre sistema e entorno interno, numa típica multiplicação de contradições irrealizáveis à tarefa de estabilização jurídica. Desta feita toda a tarefa do fenômeno do Direito é potencializada pela própria estrutura ativa de atuação do fenômeno jurídico, ou seja, o atuar do direito é o mecanismo de complexificação da Sociedade e de refinamento dos mecanismos de obstacularização que a Sociedade produz como seu subproduto a serem estabilizadas pelo Direito.

A problemática relação estabelecida entre o Direito e a Sociedade, enquanto autorelacionar [Selbstverhältnis], equaliza-se pelo fato de que segundo Neves

[...] nos termos da concepção luhmanniana da positividade do direito, isto é, fechamento normativo e abertura cognitiva do direito moderno, o problema da justiça é reorientado para a questão da complexidade adequada do sistema jurídico e da consistência de suas decisões"(2008, 85).

Esta aparente autonomia operacional do subsistema Direito face ao subsistema Sociedade pela via de uma Justiça como fórmula de dissipação da contingência não resolve o problema, antes o mascara, pois as contradições sociais não se mostram solucionáveis pelo sistema de Direito tal como se estrutura hodiernamente, ao contrário demonstra-se uma subsunção do subsistema Sociedade no subsistema Direito.

A Fórmula Luhmanniana propõe-nos um modelo orientado a solucionar a tensão existente entre Sociedade e Direito mediante a subordinação do Subsistema Sociedade pelo Subsistema Direito enquanto detentor dos códigos de esvaziamento do conflito e da contingência, contudo, tal alternativa ao invés de equalizar o subsistema sociedade o constranger a se adequar aos distintos padrões do subsistema Direito numa

8 Parece-nos que a leitura de Höffe não é capaz de apreensão adequada da complexa tradução conceitual da realidade operada por Luhmann, segundo compreendemos tal leitura não se sustenta face a percuciente exegese elaborada por M. Neves em sua obra clássica Entre Têmis e Leviatã: uma relação difícil. 
espécie de tarefa de Sísifo. Em Luhmann, parece-nos haver um erro grave: a ordem das razões está sempre em descompasso com a facticidade.

\section{A guisa de conclusão}

A filosofia política é o amor ao saber da polis, ou melhor, é a busca pela autoexplicitação das estruturas normativas da ação social nos contextos interacionais. Após percorrer as sendas e conclusões a que chegaram dois dos maiores pensadores da história da filosofia política, o primeiro um homem do século das revoluções pela liberdade e o segundo um homem das revoluções científicas, nos deparamos com uma conclusão um tanto quanto pessimista ou mesmo cética, pois, nem a diagnose hegeliana das contradições sociais e da emergência do Direito enquanto núcleo aglutinador da modernidade/contemporaneidade resultando numa eticidade [Sittlichikeit] perdida em seus extremos - mediante a irreconciliável tensão do social ao estágio do político na relação entre sociedade e direito - nem a proposta luhmanniana de uma compreensão da realidade como resultante do interrelacionar-se de diversos subsistemas operando e se interconectando segundo códigos próprios, subordinando a sociedade ao direito num acoplamento funcional e cognitivo, mostram-se capazes, segundo nossa leitura, ao enfrentamento dos graves dilemas oriundos da relação entre sociedade e direito na atualidade.

A extrema diferenciação a que passa a sociedade face a intensa unificação do direito supostamente local na sociedade global, gera ou vem gerando segundo nossa análise a impossibilidade de reconciliação do social ou da sociedade enquanto esfera irredutível ao direito, ao mesmo tempo que diuturnamente demonstra o direito como mecanismo incapaz de redução da contingência e da insegurança em franco descompasso com os ditames aos quais o ordenamento jurídico se designa e propõe.

Deste modo concluímos com uma impressão metafórica de que estamos na iminência de um ressurgir do lendário Behemoth face ao Leviatã a que se tornou o mundo moderno, tal qual descrito nas metáforas bíblicas, Hobbesianas e Schmittianas. 


\section{Referências bibliográficas}

BLOCH, E. Über Methode und System bei Hegel. Frankfurt am Main: Suhrkamp, 1970.

COSTA, D. V. C. R. M. Hegel: Liberdade e Razão. Olinda: Livro Rápido, 2003.

. L'effectif et le rationnel - Hegel et l'esprit objectif [resenha]. Kriterion. 2009, vol.50, n.119, pp. 275-280.

JERMANN, C. Spekulation und Erfahrung - Anspruch und Leistung von Hegels Rechtsphilosophie. Stuttgart: Frommann-holzboog, 1987.

HEGEL, G.W.F. Werke in 20 Bänden. Frankfurt am Main: Suhrkamp Verlag 1970, CD-ROM, versão 2.0.

Enciclopédia das Ciências Filosóficas. Tomos I, II e III. Trad. Paulo Meneses.

São Paulo: Loyola, 2001.

HÖFFE, O. Gerechtigkeit: eine philosophische Einführung. München: Verlag C.H. Beck, 2007.

HONNETH, A. Leiden an Unbestimmtheit - Eine Reaktualisierung der Hegelschen Rechtsphilosophie. Stuttgart: Reclam, 2001.

Kampf um Anerkennung. Zur moralen Grammatik sozialer Konflikte.

Frankfurt,1992.

KERVEGAN, J.-F. L'effectif et le rationnel - Hegel et l'esprit objectif. Paris: Vrin, 2008.

LUHMANN, N. Die Gesellschaft der Gesellschaft. Frankfurt am Main: Suhrkamp, 1997 [Zwei Bände]

. Sistemas Sociales. México: Anthropos/Universidad Iberoamericana, 1998.

. El derecho de la sociedad. México: Universidad Iberoamericana, 2003.

. Sociologia do Direito I e II. Rio de Janeiro: Tempo Brasileiro:1983.

NEVES, M. Entre Têmis e Leviatã: uma relação difícil - O Estado Democrático de

Direito a partir e além de Luhmann e Habermas. São Paulo: Martins Fontes, 2006.

ONNASCH, E.-O. System und Methode in der Hegels Philosophie. In: Logik, Mathematik und Natur im objektiven Idealismus: Festschrift für Dieter Wandschneider. Wurzburg: Königshausen \& Neumann, 2004, p. 79-90.

RASCH, W. Niklas Luhmann's modernity: the paradoxes of differentiation. California: Stanford Univerty Press, 2000.

RITTER, J. Metaphysik und Politik - Studien zu Aristoteles und Hegel. Frankfurt am Main: Suhrkamp, 1969. 
SIEP, L. Die Aktualität der praktischen Philosophie Hegels. In: WELSCH, W.; VIEWEG, K. (Hrsg.). Das Interesse des Denkens. Hegel aus heutiger Sicht. München: Fink, 2003, S. 191-204.

- Esprit objectif et évolution sociale. Hegel et la philosophie sociale contemporaine. In: BIENENSTOCK, M.; CRAMPE-CASNABET, M. (Hrsg.). Dans quelle mesure la philosophie est pratique. Fichte, Hegel. Paris: ENS Éditions, 2000. STEKELER-WEITHOFER, P. Philosophie des Selbstbewusstseins - Hegel System als Formanalyse von Wissen und Autonomie. Frankfurt am Main: Suhrkamp, 2005. TRINDADE, A. Para entender Luhmann e o Direito como sistema autopoiético. Porto Alegre: Livraria do Advogado, 2008. 